\title{
Study on the Creep Characteristics of Sericite Schist in the Northwest of Hubei Province
}

\author{
LIU Shang Ge $\mathrm{Ge}^{1, \mathrm{a}}$, LI Zhen ${ }^{2, \mathrm{~b}}$ and YIN Xiu Wen ${ }^{3, \mathrm{c}}$ \\ ${ }^{1}$ State Key Laboratory of Geomechanics and Geotechnical Engineering, Institute of Rock and Soil \\ Mechanics, Chinese Academy of Sciences, Wuhan, China \\ ${ }^{2}$ Opening Laboratory for Deep Mining Construction, School of Civil Engineering, Henan Polytechnic \\ University, Jiaozuo, China \\ ${ }^{3}$ Shandong Hean Geological \& Mineral Survey Co., Ltd. Weifang, China \\ a sgliu@whrsm.ac.cn, ${ }^{b}$ zhenli@hpu.edu.cn, ${ }^{c}$ yvette999@163.com
}

Keywords: Schist; Creep; Saturated Softening; Time dependent deformation; Constitutive Model. Abstract. This study explores the creep behaviors of schist in different water contents and establish the creep model and its constitutive equations. Firstly, the time-dependent deformation regularity of surrounding rock was studied based on the sericite schist tunnel construction in northwest area of Hubei Province of China. Then rock samples were taken and shear creep tests were carried out along the direction of schistosity plane in natural and saturated states. Based on the in-situ and laboratory tests results, a viscoelastic-plastic creep model was constructed through model identification and introducing a nonlinear rheological component. Finally, parameters of the creep model were obtained by multiple regression and back analysis and the rationality of the creep model was verified by comparing with the experimental data.

\section{Introduction}

Schist is a metamorphic rock with obvious lamellar structure that often be revealed in underground engineering construction. For example, in the construction of highway tunnels in the northwest area of Hubei Province of China soft schist is widely distributed. Because that the distance between schistosity planes is small and the binding power is weak, the compressive and shear strength of schist mass is low. In the influence of chlorite, montmorillonite and other clay minerals schist is easy to weathering and softening when containing water. The stability of surrounding rock is poor and the deformation of rock mass is large in the process of tunnel excavation especially under the condition of rich in groundwater, so disasters as large deformation of surrounding rock and tunnel collapse happens frequently. The long-term stability of engineering rock mass is affected significantly by its rheological property. Therefore, it is of great significance to realize the characteristics and regularities of the creep behaviors of schist and its creep mechanism in or-der to controlling the deformation and preventing disasters and ensuring the safety of the tunnel operation.

Schist is water-sensitive that water content has significant effects on the strength and de-formation parameters of rock mass. Some studies indicate that both the peak strength and the residual strength of schist decreased significantly in saturated than in dry condition. Reduce of the strength of schist impacts its rheological deformation characteristics in response. When the stress increased to the stage of yield, the plastic deformation increases with the increase of loading which induce the acceleration of the breakdown of rock. In recent year, some researchers have attempted to take the water content into account in creep test of the rocks. So, it is necessary to consider the influence of water content in studying the creep characteristics of schist.

This study is based on the sericite schist tunnel construction in northwest area of Hubei Province of China. Shear creep tests are carried out along the direction of schistosity plane under natural and saturated sates. Based on the laboratory tests results, a creep model and its constitutive equation is constructed. Finally, the creep mechanical parameters are obtained and the rationality of the model is verified. 


\section{Creep Characteristics of Schist}

Creep test. In order to study the creep characteristics of the schist furtherly, rock samples were taken from tunnel and shear creep tests were carried out along the direction of schistosity plane under natural and saturated states. The cylindrical test specimens of sericite schist were shown as Fig.1. The test used stepwise shear loading method when the normal loading keeping constant. Firstly, applied normal loading to the predicted value and keep it constant. Then applied the shear loading step by step when the normal deformation tended to be stable. Each step of loading was needed to persist more than 6 days and the water con-tent must be kept constant. Measured the instantaneous deformation when applying each step of shear loading and measured the shear deformation every at the time of 5 , 10, 30 minutes, 1, 2, 4, 8, 12, 16, 24 hours after the loading. Then measured the shear deformation every day. The shear loading values were $20 \mathrm{MPa}, 32 \mathrm{MPa}, 48 \mathrm{MPa}, 64 \mathrm{MPa}$ and $80 \mathrm{MPa}$. The creep curves of the tests of sericite schist were shown as Fig.2.

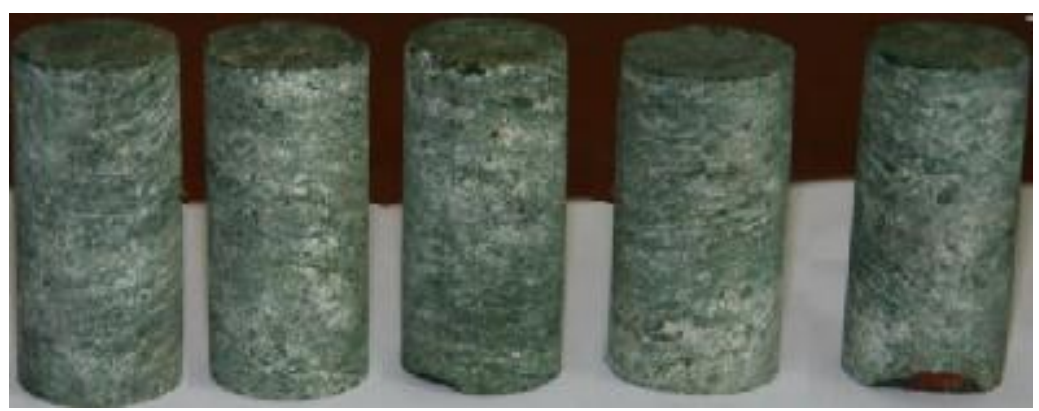

Fig.1 The cylindrical test specimens of sericite schist

Creep curve analysis. It can be seen from Fig.2 that at the instant of applying the shear loading the schist specimen generated elastic strain which increase with the increase of horizontal stress. The stage from elastic deformation to creep deformation persisted only for a moment. When the shear stress is small the deformation induced by each step of shear loading was instantaneous while the creep deformation was small and the creep rate decreased rapidly. With the increase of shear stress, the creep rate decreased to a steady value and persisted until the next step of loading. The steady creep rates were different depending on the shear stress. The shape of the creep curve especially the decelerating creep stage was influenced by the shear stress that the curve changed from approximate straight line into notch curve with the increase of the shear stress. The viscosity resistance de-creased rapidly and the specimen trended to fail when the shear deformation of the specimen increased to a certain value while the shear stress remaining at $80 \mathrm{MPa}$. Obviously, the regularity of the creep deformation of schist specimen was similar to the regularity of the deformation of schist tunnel rock mass.
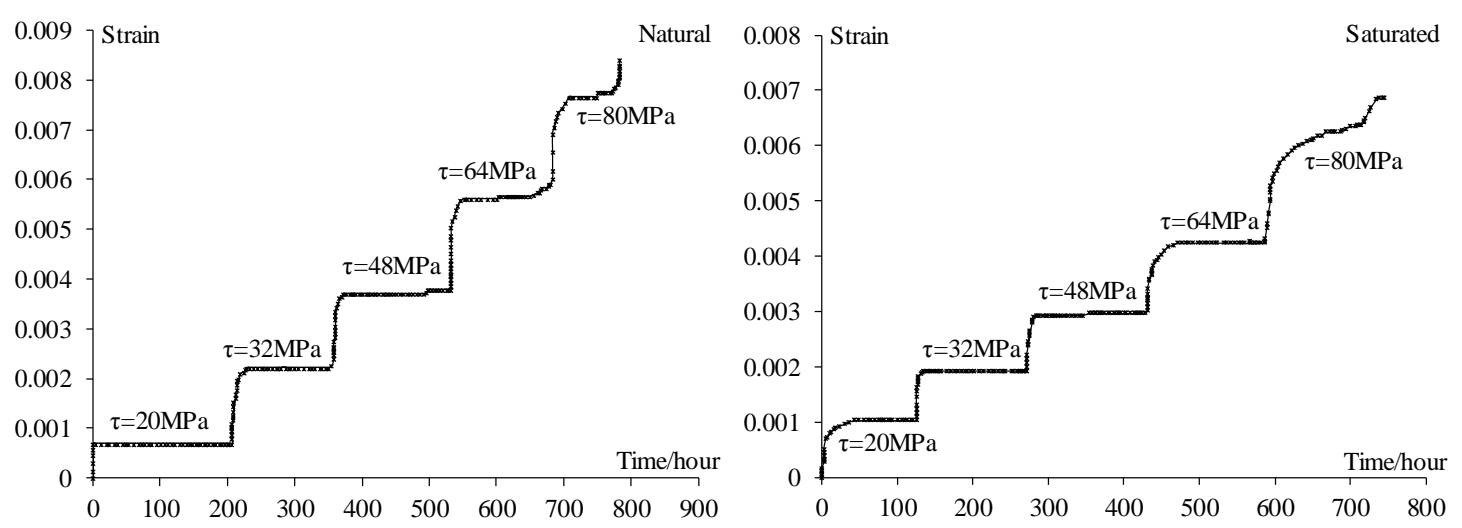

Fig.2 Creep curves of sericite schist both in natural and saturated states under different loading 
Because that the creep test used stepwise loading method, the plastic deformation caused by last step of loading would have an effect on the shear deformation generated by the next step of loading and the shear creep deformation might decrease on the contrary when the stress increased. This result gone against the creep behaviors of rock mass. So, the influence of loading history to shear deformation must be taken into consideration in processing the test data. The creep curves separated from the whole loading process that dislodged the influence of loading history were shown as Fig.3.
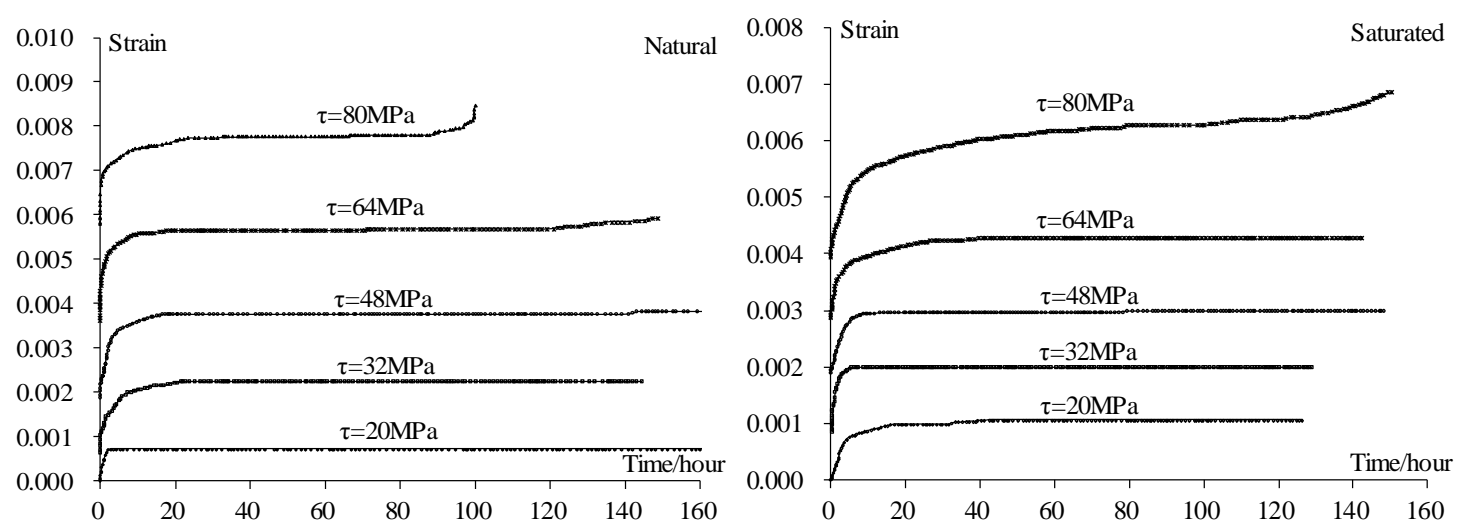

Fig. 3 Separated creep curves of sericite schist both in natural and saturated states under different loading dislodged the influence of loading history

\section{Creep Model and the Constitutive Equation}

Creep Mode. Considering both the regularities of creep curve of laboratory tests and the in-situ deformation tests, a modified viscoelastic-plastic model was chosen to describe the creep characteristics of schist by model identification. The generalized Kelvin model was suited to describe the steady creep stage when the stress was low while a nonlinear rheological component must be introduced to described the accelerating creep stage of schist when the stress is higher than a certain value. The relation between the strain and time of the nonlinear rheological component was indicated as follows.

$$
\begin{aligned}
& e(t)=\frac{\sigma}{G}\left(1-e^{-\left(\frac{H\left(t-t_{2}\right)}{t_{c}-t_{2}}\right)^{n}}\right) \\
& H\left(t-t_{2}\right)= \begin{cases}0 & t \leq t_{2} \\
t-t_{2} & t>t_{2}\end{cases}
\end{aligned}
$$

Where $G, n$ is rheological parameters; $t_{2}$ is the time from steady creep to accelerating stage; $t$ is the time of shear failure.

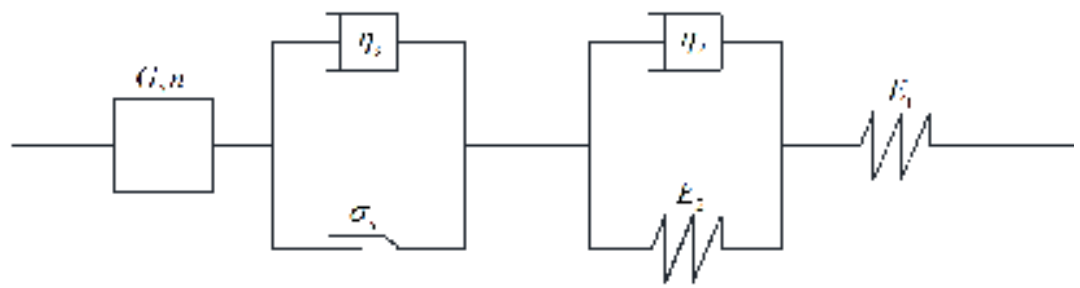

Fig.4 The nonlinear viscoelastic-plastic creep model of schist contains six components 
Constitutive Equations. Based on the creep model of schist be composed of 6 basic models, the constitutive equations of the nonlinear viscoelastic-plastic creep model of schist constructed by model identification were shown as Equation 3 to 5.

If $\sigma \leq \sigma_{s}$,

$e(t)=\frac{s}{E_{1}}+\frac{s}{E_{2}}\left(1-e^{-\frac{E_{2}}{h_{2}} t}\right)$

If $\sigma>\sigma_{s}$,

$$
\begin{aligned}
& t \leq t_{2}, \quad \varepsilon(t)=\frac{\sigma}{E_{1}}+\frac{\sigma}{E_{2}}\left(1-\varepsilon^{-\frac{E_{2}}{\eta_{2}} t}\right)+\frac{\sigma-\sigma_{s}}{\eta_{s}} t \\
& t>t_{2}, \quad \varepsilon(t)=\frac{\sigma}{E_{1}}+\frac{\sigma}{E_{2}}\left(1-\varepsilon^{-\frac{E_{2}}{\eta_{2}} t}\right)+\frac{\sigma-\sigma_{s}}{\eta_{s}} t+\frac{\sigma}{G}\left(1-\varepsilon^{\left.-\left(\frac{H\left(t-t_{2}\right)}{t_{c}-t_{2}}\right)^{n}\right)}\right)
\end{aligned}
$$

Where $E_{1}=$ instantaneous shear modulus, $E_{2}=$ viscoelasticity shear modulus, $\sigma_{\mathrm{s}}=$ frictional resistance.

The follow equations are used to describe the shear creep characteristics of schist in high stress.

$$
\begin{aligned}
& t \leq t_{2}, \quad \varepsilon(t)=\frac{\tau}{E_{1}}+\frac{\tau}{E_{2}}\left(1-\varepsilon^{-\frac{E_{2}}{\eta_{2}} t}\right)+\frac{\tau-\tau_{s}}{\eta_{s}} t \\
& t>t_{2}, \quad \varepsilon(t)=\frac{\tau}{E_{1}}+\frac{\tau}{E_{2}}\left(1-\varepsilon^{-\frac{E_{2}}{\eta_{2}} t}\right)+\frac{\tau-\tau_{s}}{\eta_{s}} t+\frac{\tau}{G}\left(1-\varepsilon^{\left.-\left(\frac{H\left(t-t_{2}\right)}{t_{c}-t_{2}}\right)^{n}\right)}\right)
\end{aligned}
$$

Calculating of Parameters. Multiple regression analysis was used to obtain the parameters of the creep constitutive equations based on the test data that processed with Boltzmann superposition principle to analyze the regularities of these parameters. Then these parameters were plugged into equation 6 and 7 and the optimal parameters were obtained by back analysis.

Table 1 Parameters of the creep constitutive equations of schist both in natural and saturated states by back analysis

\begin{tabular}{ccccccccc}
\hline \multirow{2}{*}{ Parameters } & $\tau$ & $E_{1}$ & $E_{2}$ & $\mu_{2}$ & $\mu_{2}$ & $G$ & $n$ & $R$ \\
\cline { 2 - 9 } & {$[\mathrm{MPa}]$} & {$[\mathrm{GPa}]$} & {$[\mathrm{GPa}]$} & {$[\mathrm{GPa} \bullet \mathrm{h}]$} & {$[\mathrm{GPa} \bullet \mathrm{h}]$} & {$[\mathrm{GPa}]$} & - & - \\
\hline \multirow{5}{*}{ Natural } & 18 & 5.34 & 13.56 & 32.45 & - & - & - & $1.02 \mathrm{e}-5$ \\
\cline { 2 - 9 } & 32 & 6.75 & 24.20 & 30.56 & - & - & - & $4.56 \mathrm{e}-6$ \\
\cline { 2 - 9 } & 48 & 9.82 & 30.25 & 78.25 & - & - & - & $3.25 \mathrm{e}-5$ \\
\cline { 2 - 9 } & 64 & 9.87 & 21.23 & 50.56 & - & - & - & $4.40 \mathrm{e}-5$ \\
\cline { 2 - 9 } & 80 & 10.02 & 35.24 & 65.45 & 75.26 & & & $3.25 \mathrm{e}-6$ \\
\hline \multirow{5}{*}{ Saturated } & 80 & 10.89 & 26.47 & 60.47 & 58.90 & 16.25 & 17 & $2.60 \mathrm{e}-5$ \\
\cline { 2 - 9 } & 18 & 6.68 & 11.56 & 26.16 & - & - & - & $3.69 \mathrm{e}-5$ \\
& 32 & 7.35 & 23.77 & 46.50 & - & - & - & $1.90 \mathrm{e}-5$ \\
\cline { 2 - 9 } & 48 & 6.95 & 50.46 & 38.29 & - & - & - & $6.20 \mathrm{e}-5$ \\
\cline { 2 - 9 } & 64 & 8.56 & 31.35 & 68.44 & - & - & - & $7.90 \mathrm{e}-5$ \\
\cline { 2 - 8 } & 80 & 9.11 & 45.60 & 74.28 & 62.33 & - & - & $8.25 \mathrm{e}-5$ \\
\hline
\end{tabular}


Parameters of the creep constitutive equations of schist both in natural and saturated states by back analysis were shown in Table 1 . The creep hook face was obtained by plugging the parameters into equation 6 and 7 and the rationality of it was verified by comparing with the test curves.

Therefore, the creep model shown in Figure 5 and the constitutive equations can be used to analysis the time-dependent deformation and damage mechanism of schist rock mass in construction of tunnel or other underground engineering.

\section{Conclusions}

In-situ displacement and experimental creep tests were carried out to study the characteristics of schist both in nature and saturated states and the creep model and its constitutive equations were established. The main conclusions were shown as bellow.

The process of deformation development of schist tunnel rock can be divided into three stages includes the initial stage of rapidly growth, the stage of slowly growth and the stage of reaching a steady.

The viscosity resistance decreased rapidly and the specimen trended to fail when the shear deformation of the specimen increased to a certain value while the shear stress remaining at $80 \mathrm{MPa}$. The regularity of the creep deformation of schist specimen was similar to the regularity of the deformation of schist tunnel rock mass.

The modified viscoelastic-plastic model by model identification and introducing a non-linear rheological component was reasonable to describe the creep characteristics of schist.

\section{Acknowledgements}

The authors gratefully acknowledge the support by the National Key Research and Development Project of China (2016YFC0401802), the State Key Program of National Natural Science of China (51539002) and the Natural Science Foundation of Hubei Province of China (2016YFC040180).

\section{References}

[1] Khandelwal M, Singh TN. 2009. Predicting elastic properties of schistose rocks from unconfined strength using intelligent approach. Arabian Journal of Geosciences 4(3-4):435-442.

[2] Lajtai E Z, Schmidtke R H, Bielus L P. 1987. The effect of water on the time-dependent deformation and fracture of a granite. International Journal of Rock Mechanics and Mining Sciences \& Geomechanics Abstracts 24(4): 247-255.

[3] Xiong L, Li T, Yang L. 2014. Biaxial compression creep test on green-schist considering the effects of water content and anisotropy. KSCE Journal of Civil Engineering 18(1): 103-112.

[4] Liu L, Wang G-m, Chen J-h, Yang S. 2013. Creep experiment and rheological model of deep saturated rock. Transactions of Nonferrous Metals Society of China 23 (2): 478-483.

[5] Bikong C, Hoxha D, Shao J F. 2015. A micro-macro model for time-dependent behavior of clayey rocks due to anisotropic propagation of microcracks. International Journal of Plasticity 69: 73-88.

[6] Read S AL, Perrin N D, Brown I. R. 1987. Measurement and analysis of laboratory strength and deformability characteristics of schistose rocks. 6th ISRM Congress. Montreal: International Society for Rock Mechanics.

[7] Yang S Q, Jing H W, Cheng L. 2014. Influences of pore pressure on short-term and creep mechanical behavior of red sandstone. Engineering Geology 179: 10-23. 